\title{
Arranjo de plantas na expressão dos componentes da produtividade de grãos de canola
}

\author{
Cleusa Adriane Menegassi Bianchi Krüger(1), José Antonio Gonzalez da Silva(1), Sandro Luis Petter Medeiros ${ }^{(2)}$, \\ Genei Antonio Dalmago ${ }^{(3)}$, César Oneide Sartori ${ }^{(1)}$ e Jordana Schiavo ${ }^{(1)}$ \\ (1)Universidade Regional do Noroeste do Estado do Rio Grande do Sul, Departamento de Estudos Agrários, Rua do Comércio, \\ no 3.000, CEP 98700-000 ljuí, RS. E-mail: cleusa_bianchi@yahoo.com.br, jagsfaem@yahoo.com.br, cesar.sartori@unijui.edu.br, \\ jordana.s09@gmail.com (2)Universidade Federal de Santa Maria, Centro de Ciências Rurais, Departamento de Fitotecnia, \\ CEP 97105-900 Santa Maria, RS. E-mail: slpmedeiros@yahoo.com.br ${ }^{(3)}$ Embrapa Trigo, Caixa Postal 451, CEP $99001-970$ Passo Fundo, RS. \\ E-mail: dalmago@cnpt.embrapa.br
}

Resumo - O objetivo deste trabalho foi avaliar os efeitos do arranjo de plantas nos componentes diretos da produtividade de grãos e na produção final em canola, com uso de híbridos de diferentes ciclos de desenvolvimento. Foram realizados três experimentos com espaçamento entre linhas de 0,20, 0,40 e 0,60 m, em delineamento experimental de blocos ao acaso, com quatro repetições para cada ano de cultivo (2008 e 2009), genótipo (Hyola 432 e Hyola 61) e densidade de plantas (20, 40, 60 e 80 plantas por metro quadrado). Hyola 432 apresentou maior produção de grãos em comparação a Hyola 61, independentemente do ano e da densidade de cultivo. Os efeitos do ano de cultivo influenciaram mais a produção e os componentes da produtividade de grãos do que o potencial genético da cultivar e a densidade de cultivo. $\mathrm{O}$ ajuste da densidade de plantas em canola é alterado pelo genótipo e pelo ano de cultivo.

Termos para indexação: Brassica napus, densidade de plantas, interação genótipo x ambiente.

\section{Plant arrangement in the expression of yield components of canola}

\begin{abstract}
The objective of this work was to evaluate the effects of plant arrangement on direct yield components and final production in canola, using hybrids of different development cycles. Three experiments were carried out with row spacing of $0.20,0.40$, and $0,60 \mathrm{~m}$, in a randomized block design, with four replicates for each cultivation year (2008 and 2009), genotype (Hyola 432 and Hyola 61), and plant density (20, 40, 60, and 80 plants per square meter). Hyola 432 showed higher grain yield than Hyola 61, independently of year and plant density. The effects of years of cultivation influenced grain production and yield components more than the genetic potential of the cultivar and planting density. The adjustment of plant density in canola is altered by genotype and years of cultivation.
\end{abstract}

Index terms: Brassica napus, plant density, genotype x environment interaction.

\section{Introdução}

A herança genética para produtividade de grãos é muito complexa, pois vários genes de pequeno efeito atuam na sua expressão, com ação nos processos fisiológicos de interferência direta ou indireta na produção final (Silveira et al., 2010). A produtividade de grãos em canola (Brassica napus L.) é resultante dos componentes: número de plantas por unidade de área, número de síliquas por planta, número de grãos por síliqua e massa média de grão (Thomas, 2003). A expressão desses componentes é dependente das cultivares e do ambiente de cultivo. Entre os fatores diretamente ligados ao ambiente, a melhoria do manejo de cultivo pode proporcionar efeitos benéficos na produtividade de grãos. A modificação no arranjo de plantas via espaçamento entre linhas ou entre plantas na linha pode ser alternativa para se alcançar maior produtividade de grãos em canola.

$\mathrm{Na}$ canola de inverno, a compensação em baixas densidades de plantas é obtida por meio da produção de maior área foliar e da maior produção de ramos e síliquas por plantas (Diepenbrock, 2000). O aumento da densidade de plantas nessa espécie tende a afetar tanto os componentes da produtividade de grãos, com modificações no conteúdo de óleo e redução no índice de colheita da cultura (Leach et al., 1999; Angadi et al., 2003), como a maior estabilidade e uniformidade na produtividade de grãos, que é considerada mais estável quando as plantas estão uniformemente distribuídas (Shahin \& Valiollah, 2009). 
Entretanto, informações sobre o arranjo de plantas para as cultivares de canola atualmente recomendadas para o cultivo no Sul do Brasil são escassas. Conforme os indicativos tecnológicos para a cultura da canola (Tomm, 2007), deve-se buscar distribuição de sementes que forneça a população de 40 plantas por metro quadrado. No entanto, a canola tem grande capacidade de compensar baixas populações de plantas com desempenhos adequados, inclusive ao redor de 15 plantas por metro quadrado. Além disso, é recomendado, no distanciamento entre linhas, o menor espaçamento possível da semeadora. Contudo, semeadoras com discos alveolados e com sulcadores têm mostrado bom desempenho em espaçamentos de até $45 \mathrm{~cm}$.

É importante ressaltar que a maioria dos estudos de canola existentes trata de variedades (populações) (Santos et al., 2000) ou de híbridos provenientes de outros países (Coimbra et al., 2004), de resposta diferente em relação aos genótipos, na maioria híbridos, utilizados atualmente em escala comercial (Dalmago et al., 2010). Portanto, mais pesquisas são necessárias.

O objetivo deste trabalho foi avaliar os efeitos do arranjo de plantas nos componentes diretos da produtividade de grãos e na produção final em canola, com uso de híbridos de diferentes ciclos de desenvolvimento.

\section{Material e Métodos}

Os experimentos foram conduzidos nos anos agrícolas de 2008 e 2009 no Instituto Regional de Desenvolvimento Rural, do Departamento de Estudos Agrários da Universidade Regional do Noroeste do Estado do Rio Grande do Sul (Unijuí), no Município de Augusto Pestana, RS (28 $26^{\prime} 30^{\prime \prime} \mathrm{S}$ e $54^{\circ} 00^{\prime} 58^{\prime \prime} \mathrm{W}$, com altitude média de $298 \mathrm{~m}$ ). O solo da área experimental é classificado como Latossolo Vermelho distroférrico típico (Santos et al., 2006), e o clima da região, segundo a classificação de Köppen, é do tipo Cfa, com verão quente e sem estação seca.

Foram realizados três experimentos, com três espaçamentos entre linhas: 0,20, 0,40 e 0,60 m. Em cada experimento, utilizou-se o delineamento experimental de blocos ao acaso, com quatro repetições e arranjo fatorial $2 \times 2 \times 4$ que consistiu em: dois anos de cultivo (2008 e 2009), dois genótipos (Hyola 432 e Hyola 61) e quatro densidades de plantas (20, 40,
60 e 80 plantas por metro quadrado), respectivamente. A unidade experimental foi constituída de cinco linhas de cinco metros de comprimento, e a dimensão das parcelas experimentais foi alterada de acordo com o espaçamento entre linhas adotado, com parcelas de $5 \mathrm{~m}^{2}(0,20 \mathrm{~m}), 10 \mathrm{~m}^{2}(0,40 \mathrm{~m})$ e $15 \mathrm{~m}^{2}(0,60 \mathrm{~m})$.

A correção do solo e a adubação de cobertura foram feitas de acordo com os resultados da análise de solo, tendo-se considerado produtividade de grãos de aproximadamente $1.500 \mathrm{~kg} \mathrm{ha}^{-1}$. A adubação de cobertura foi de $60 \mathrm{~kg} \mathrm{ha}^{-1}$ de $\mathrm{N}$, fonte ureia, no estádio fenológico de quatro folhas desenvolvidas (Meier, 2001), conforme indicações técnicas para a cultura da canola (Tomm, 2007). A semeadura foi realizada, nos dois anos, na terceira semana de maio, de forma manual, com quantidade de sementes superior à mínima necessária. No estádio 1, de duas a três folhas (Meier, 2001), as plantas foram desbastadas para obter as densidades de plantas desejadas para o experimento.

As variáveis mensuradas foram: produtividade de grãos (PG), obtida pela colheita manual total da parcela e convertida em $\mathrm{kg} \mathrm{ha}^{-1}$; e massa de mil grãos (MMG), em gramas, determinada pela pesagem de amostra de 250 grãos coletados aleatoriamente do volume colhido na parcela, multiplicado por quatro. Para a avaliação dos demais componentes da produtividade de grãos, foram retiradas de cada unidade experimental cinco plantas colhidas de forma aleatória, para compor a média das seguintes determinações: número de síliquas por planta (NSP), em unidade, obtido pela contagem das síliquas de cada planta; e número de grãos por síliquas (NGS), em unidade, determinado pela coleta, ao acaso, de 20 síliquas por planta.

Os dados foram submetidos à análise de variância (teste $\mathrm{F}$, a $5 \%$ de probabilidade) e ao teste de médias (Tukey, a 5\% de probabilidade), e os efeitos da densidade de plantas foram avaliados por análise de regressão, a $5 \%$ de probabilidade. Todos os procedimentos estatísticos foram realizados com auxílio do programa Genes (Cruz, 2001).

\section{Resultados e Discussão}

No espaçamento de $0,20 \mathrm{~m}$, foram observadas diferenças significativas nos efeitos principais ano e genótipo, em relação à PG em canola (Tabela 1). A densidade de plantas não influenciou a $P G$, independentemente do espaçamento entre linhas 
utilizado, o que indica que podem ocorrer alterações nos demais componentes, com estabilização da PG, o que é conhecido como plasticidade fenotípica (Sultan, 2000). A interação genótipo $\mathrm{x}$ densidade apresentou o maior quadrado médio (QM) quanto à alteração da PG. Esse tipo de resposta também foi observado em outras culturas produtoras de grãos, como soja, milho

Tabela 1. Análises de variância para produtividade de grãos (PG), massa de mil grãos (MMG), número de síliquas por planta (NSP) e número de grãos por síliqua (NGS), em canola, no espaçamento de 0,20, 0,40 e 0,60 m entre linhas.

\begin{tabular}{|c|c|c|c|c|c|}
\hline \multirow[t]{2}{*}{ Fonte de variação } & \multirow[t]{2}{*}{ GL } & \multicolumn{4}{|c|}{ Quadrado médio } \\
\hline & & $\mathrm{PG}\left(\mathrm{kg} \mathrm{ha}^{-1}\right)$ & MMG (g) & NSP & NGS \\
\hline & & & $0,20 \mathrm{~m}$ & & \\
\hline Bloco & 3 & $58.613,0$ & 0,16 & 868,0 & 1,60 \\
\hline Ano (A) & 1 & $2.954 .058,0 *$ & $0,01^{\mathrm{ns}}$ & $166.668,0^{*}$ & $108,42 *$ \\
\hline Genótipo (G) & 1 & $1289161,0^{*}$ & $0,20^{\mathrm{ns}}$ & $56.050,0^{*}$ & $28,22 *$ \\
\hline Densidade (D) & 3 & $66.923,0^{\mathrm{ns}}$ & $0,46^{\mathrm{ns}}$ & $101.062,0 *$ & $2,60^{\text {ns }}$ \\
\hline$A \times G$ & 1 & $15.860,0^{\mathrm{ns}}$ & $2,17 *$ & $14.580,0^{*}$ & $2,32^{\text {ns }}$ \\
\hline$A \times D$ & 3 & $174.526,0^{*}$ & $0,89^{\text {ns }}$ & $30.238,0^{*}$ & $2,26^{\mathrm{ns}}$ \\
\hline$G \times D$ & 3 & $391.368,0^{*}$ & $0,20^{\mathrm{ns}}$ & $24.095,0^{*}$ & $3,14^{\text {ns }}$ \\
\hline$A \times G \times D$ & 3 & $85.519,0 *$ & $0,29^{\text {ns }}$ & $13.800,0^{*}$ & $1,37^{\mathrm{ns}}$ \\
\hline Erro & 45 & $25.486,0$ & 0,34 & $2.839,0$ & 2,30 \\
\hline Total & 63 & - & - & - & - \\
\hline Média geral & - & $1.037,00$ & 3,70 & 207,00 & 16,16 \\
\hline \multirow[t]{2}{*}{ CV (\%) } & - & 19,39 & 15,90 & 25,64 & 9,38 \\
\hline & & & $0,40 \mathrm{~m}$ & & \\
\hline Bloco & 3 & $6.709,0$ & 0,30 & $13.332,0$ & 4,40 \\
\hline Ano (A) & 1 & 1.118.702,0* & $3,56^{*}$ & $85.118,0^{*}$ & $133,11 *$ \\
\hline Genótipo (G) & 1 & $890.451,0^{*}$ & $0,43^{\text {ns }}$ & $59.170,0^{*}$ & $1,78^{\mathrm{ns}}$ \\
\hline Densidade (D) & 3 & $13.413,0^{\text {ns }}$ & $0,25^{\mathrm{ns}}$ & $42.154,0^{*}$ & $0,68^{\mathrm{ns}}$ \\
\hline $\mathrm{A} \times \mathrm{G}$ & 1 & $547.581,0^{*}$ & $2,52 *$ & $23.409,0^{\mathrm{ns}}$ & $2,76^{\mathrm{ns}}$ \\
\hline$A \times D$ & 3 & $20.178,0^{\mathrm{ns}}$ & $0,39^{\mathrm{ns}}$ & $1.112,0^{\mathrm{ns}}$ & $2,89^{\text {ns }}$ \\
\hline G x D & 3 & $36.620,0^{\mathrm{ns}}$ & $0,49^{\text {ns }}$ & $7.998,0^{\mathrm{ns}}$ & $2,37^{\text {ns }}$ \\
\hline$A \times G \times D$ & 3 & $102.675,0^{*}$ & $0,12^{\mathrm{ns}}$ & $3.628,0^{\mathrm{ns}}$ & $2,87^{\text {ns }}$ \\
\hline Erro & 45 & $29.442,0$ & 0,20 & $5.035,0$ & 2,23 \\
\hline Total & 63 & - & - & - & - \\
\hline Média geral & - & 941,0 & 3,54 & 237,37 & 16,30 \\
\hline \multirow[t]{2}{*}{ CV (\%) } & - & 18,21 & 12,72 & 29,89 & 9,17 \\
\hline & & & $0,60 \mathrm{~m}$ & & \\
\hline Bloco & 3 & $51.730,0$ & 0,22 & $19.150,0$ & 7,05 \\
\hline Ano (A) & 1 & $283.729,0^{*}$ & $0,01^{\mathrm{ns}}$ & $50.323,0^{*}$ & $352,50 *$ \\
\hline Genótipo (G) & 1 & $440.613,0^{*}$ & $0,45^{\text {ns }}$ & $43.108,0^{*}$ & $1,38^{\mathrm{ns}}$ \\
\hline Densidade (D) & 3 & $12.745,0^{\text {ns }}$ & $0,67^{\mathrm{ns}}$ & $64.841,0^{*}$ & $6,23^{\text {ns }}$ \\
\hline $\mathrm{A} \times \mathrm{G}$ & 1 & $4.100,0^{\mathrm{ns}}$ & $2,48 *$ & $1.181,0^{\mathrm{ns}}$ & $7,15^{\text {ns }}$ \\
\hline$A \times D$ & 3 & $10.235,0^{\mathrm{ns}}$ & $0,24^{\mathrm{ns}}$ & $947,0^{\text {ns }}$ & $5,01^{\mathrm{ns}}$ \\
\hline $\mathrm{G} \times \mathrm{D}$ & 3 & $31.179,0^{\mathrm{ns}}$ & $0,36^{\mathrm{ns}}$ & $75.294,0^{*}$ & $6,21^{\text {ns }}$ \\
\hline$A \times G \times D$ & 3 & $10.242,0^{\text {ns }}$ & $0,20^{\mathrm{ns}}$ & $3.260,0^{\mathrm{ns}}$ & $1,72^{\mathrm{ns}}$ \\
\hline Erro & 45 & $17.305,0$ & 0,18 & $7.624,0$ & 2,11 \\
\hline Total & 63 & - & - & - & - \\
\hline Média geral & - & 848,00 & 3,73 & 331,00 & 16,52 \\
\hline CV (\%) & - & 15,51 & 11,40 & 26,33 & 8,79 \\
\hline
\end{tabular}

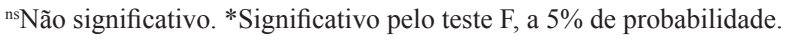

e trigo (Lima et al., 2008; Strieder et al., 2008; Silveira et al., 2010), o que mostra que a adaptabilidade e a estabilidade da PG para essas espécies estão altamente ligadas à densidade de plantas e ao ano de cultivo.

Em relação ao NSP, todas as fontes de variação foram significativas no espaçamento de $0,20 \mathrm{~m}$ (Tabela 1 ), e os valores mais expressivos de QM foram observados quanto ao ano de cultivo e à densidade de plantas. As significâncias verificadas para NGS em relação ao ano e ao genótipo indicam que o ano de cultivo e a constituição genética da cultivar tiveram maior influência na variável. A MMG foi o componente de produtividade que mostrou maior estabilidade fenotípica e não apresentou mudanças nos anos de avaliação $(0,20 \mathrm{~m})$. Portanto, o presente trabalho confirmou a tendência de a maioria das espécies vegetais apresentarem maior estabilidade no componente ligado ao enchimento de grãos, conforme Carvalho et al. (2008) e Silveira et al. (2010).

No espaçamento entre linhas de $0,40 \mathrm{~m}$, o ano de cultivo apresentou o maior valor de QM para $\mathrm{PG}$, seguido do padrão genético da cultivar, com ausência de significância para densidade de plantas (Tabela 1). Cabe destacar que foi verificada interação significativa entre ano e genótipo somente nesse espaçamento, o que indica a necessidade de avaliar o desempenho genético das cultivares quanto às alterações de ano de cultivo, quando o arranjo de plantas para essa espécie é alterado.

Os efeitos principais de ano, genótipo e densidade determinaram o NSP, enquanto o NGS foi influenciado apenas pelo ano de cultivo, no espaçamento de $0,40 \mathrm{~m}$. A MMG também variou com o ano de cultivo e com os efeitos de interação ano x genótipo (Tabela 1).

Os efeitos principais ano e genótipo influenciaram a variável $\mathrm{PG}$ no espaçamento de $0,60 \mathrm{~m}$, com maior contribuição do genótipo (Tabela 1). Esses resultados confirmam os de Johnson \& Hanson (2003) e Coimbra et al. (2004), que observaram maiores valores de efeito da cultivar na alteração da $\mathrm{PG}$, em comparação a outros fatores de ambiente, como local e ano de cultivo. $\mathrm{O}$ forte efeito no genótipo parece estar relacionado à necessidade da planta de ocupar os espaços proporcionados pelo aumento do espaçamento de semeadura.

No espaçamento de $0,20 \mathrm{~m}$, na interação ano $\mathrm{x}$ genótipo x densidade, em 2008, Hyola 432 mostrou tendência de incremento na PG em função da densidade 
de plantas (Tabela 2), ao contrário de Hyola 61, que não apresentou alteração. Em 2009, Hyola 432 apresentou a mesma tendência que em 2008, enquanto Hyola 61 mostrou tendência linear, com redução na PG. O fato de a maior produtividade de grãos ter ocorrido em 2009 pode estar relacionado à maior precipitação pluvial (total no ciclo, $1.124 \mathrm{~mm}$ ), principalmente durante o enchimento de grãos, enquanto em 2008, a precipitação pluvial durante o ciclo da cultura foi de $967 \mathrm{~mm}$ e o maior volume acumulado ocoreu durante a fase de maturação.

Em relação ao NSP, na interação ano $\mathrm{x}$ genótipo $\mathrm{x}$ densidade, no espaçamento de $0,20 \mathrm{~m}$, houve tendência linear para redução nessa característica, independentemente dos anos e dos genótipos avaliados (Tabela 2). Em relação ao NGS, no efeito principal genótipo, diferenças significativas entre genótipos foram observadas apenas na menor densidade de cultivo, com valores de 18 e 15 NGS para Hyola 61 e Hyola 432, respectivamente. Quanto ao efeito principal ano de cultivo, o NGS foi significativamente superior em 2008 (17 grãos por síliqua), em comparação a 2009 (14 grãos por síliqua).

Para cada nível tecnológico utilizado em cultivos agrícolas, Leach et al. (1999), ao avaliar canola de inverno com populações na faixa de 50 a 100 plantas por metro quadrado, observaram que a combinação densidade de plantas e espaçamento reduzido foi decisiva para maior PG. Porém, em maiores densidades, esses efeitos não se confirmaram, em virtude de pragas e doenças e da competição inter e intraespecífica por água, nutrientes e radiação. Angadi et al. (2003) relataram que houve maximização do NSP na menor densidade, em canola de primavera, fato atribuído à boa disponibilidade hídrica, e que os componentes NGS e MMG não foram modificados. Entretanto, Johnson \& Hanson (2003) não constataram aumento na PG de canola com uso de menor espaçamento, o que pode ser explicado pelas interações entre o ambiente de cultivo e o padrão genético da cultivar.

No espaçamento de $0,40 \mathrm{~m}$, na interação ano x genótipo x densidade, em 2008, Hyola 432 não

Tabela 2. Produtividade de grãos $\left(\mathrm{kg} \mathrm{ha}^{-1}\right)$ e número de síliquas por planta, em canola, nos espaçamentos de $0,20,0,40$ e 0,60 m entre linhas, em função dos efeitos principais e das interações de anos, genótipos e densidades de 20, 40, 60 e 80 plantas por metro quadrado ${ }^{(1)}$.

\begin{tabular}{|c|c|c|c|c|c|c|c|}
\hline \multirow[t]{2}{*}{ Ano } & \multirow[t]{2}{*}{ Genótipo } & \multicolumn{4}{|c|}{ Densidade (plantas por metro quadrado) } & \multirow[t]{2}{*}{ Regressão } & \multirow[t]{2}{*}{$\mathrm{R}^{2}$} \\
\hline & & 20 & 40 & 60 & 80 & & \\
\hline & & \multicolumn{6}{|c|}{ Produtividade de grãos, $0,20 \mathrm{~m}$ entre linhas } \\
\hline 2008 & Hyola 432 & $781,75 \mathrm{a}$ & $856,05 \mathrm{a}$ & $923,97 \mathrm{a}$ & $1.242,29 \mathrm{a}$ & $y=583,625+7,297 x$ & $0,85^{*}$ \\
\hline 2008 & Hyola 61 & $574,29 \mathrm{a}$ & $585,72 b$ & $594,47 b$ & $608,87 \mathrm{~b}$ & ns & - \\
\hline 2009 & Hyola 432 & $1.314,54 \mathrm{a}$ & $1.211,92 \mathrm{a}$ & $1.368,65 \mathrm{a}$ & $1.743,62 \mathrm{a}$ & $\mathrm{y}=1.048,700+7,219 x$ & $0,74 *$ \\
\hline \multirow[t]{2}{*}{2009} & Hyola 61 & $1.381,12 \mathrm{a}$ & $966,14 b$ & $1.090,97 \mathrm{~b}$ & $939,14 b$ & $y=1.394,625-6,005 x$ & $0,70^{*}$ \\
\hline & & \multicolumn{6}{|c|}{ Produtividade de grãos, $0,40 \mathrm{~m}$ entre linhas } \\
\hline 2008 & Hyola 432 & $976,95 \mathrm{a}$ & $753,89 \mathrm{a}$ & $856,82 \mathrm{a}$ & $752,79 \mathrm{a}$ & ns & - \\
\hline 2008 & Hyola 61 & $636,45 a$ & $983,47 \mathrm{a}$ & $777,62 \mathrm{a}$ & $739,27 \mathrm{a}$ & $y=276,831+24,599 x-0,240 x 2$ & $0,70^{*}$ \\
\hline 2009 & Hyola 432 & $1.150,27 \mathrm{a}$ & $1.286,95 \mathrm{a}$ & $1.338,52 \mathrm{a}$ & $1.362,40 \mathrm{a}$ & $y=971,550+10,489 x-0,07 x 2$ & $0,93 *$ \\
\hline \multirow[t]{2}{*}{2009} & Hyola 61 & $886,79 \mathrm{a}$ & $852,50 \mathrm{a}$ & $883,70 \mathrm{a}$ & $831,52 \mathrm{~b}$ & ns & - \\
\hline & & \multicolumn{6}{|c|}{ Número de síliquas por planta, $0,20 \mathrm{~m}$} \\
\hline 2008 & Hyola 432 & $183,00 \mathrm{~b}$ & $147,00 \mathrm{a}$ & 136,50 & 131,50 & $y=190,750-0,825 x$ & $0,83^{*}$ \\
\hline 2008 & Hyola 61 & $234,25 \mathrm{a}$ & 158,00 & 152,25 & 179,50 & $y=238,000-0,995 x$ & $0,69 *$ \\
\hline 2009 & Hyola 432 & $303,00 \mathrm{~b}$ & $212,00 \mathrm{a}$ & $196,50 \mathrm{a}$ & $184,25 b$ & $y=316,875-1,858 x$ & $0,79 *$ \\
\hline \multirow[t]{2}{*}{2009} & Hyola 61 & $572,25 \mathrm{a}$ & $186,75 \mathrm{a}$ & $202,75 \mathrm{a}$ & $281,75 \mathrm{a}$ & $\mathrm{y}=524,750-4,277 x$ & $0,68^{*}$ \\
\hline & & \multicolumn{6}{|c|}{ Número de síliquas por planta, $0,40 \mathrm{~m}$} \\
\hline \multirow[t]{2}{*}{ - } & - & 310,93 & 194,87 & 231,93 & 211,75 & $\mathrm{y}=302,500-1,302 \mathrm{x}$ & $0,74 *$ \\
\hline & & \multicolumn{6}{|c|}{ Número de síliquas por planta, $0,60 \mathrm{~m}$} \\
\hline- & Hyola 432 & $419,50 \mathrm{a}$ & $471,50 \mathrm{a}$ & $336,00 \mathrm{a}$ & $317,37 \mathrm{a}$ & $y=496,437-2,207 x$ & $0,76^{*}$ \\
\hline - & Hyola 61 & $393,62 \mathrm{a}$ & $253,50 \mathrm{~b}$ & $222,00 \mathrm{~b}$ & $239,50 \mathrm{~b}$ & $y=400,625-2,469 x$ & $0,79 *$ \\
\hline
\end{tabular}

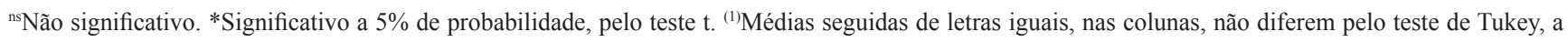
$5 \%$ de probabilidade. 
apresentou alterações na PG em função da densidade de plantas; entretanto, foi detectada equação quadrática para Hyola 61, neste ano de cultivo. Portanto, o ponto de máxima obtido pela equação $\mathrm{y}=-\mathrm{b}_{1} / 2 \mathrm{~b}_{2}$ indicou densidade de aproximadamente 51 plantas por metro quadrado. Em 2009, Hyola 61 não apresentou variação na PG com o aumento da densidade, enquanto Hyola 432 apresentou tendência quadrática com ponto de máxima de produção $\left(y=-b_{1} / 2 b_{2}\right)$ ao redor de 74 plantas por metro quadrado. Sidlaukas \& Bernotas (2003) observaram aumento da PG em canola de primavera com o incremento da densidade de plantas e decréscimo na PG a partir de uma população de 50-60 plantas por metro quadrado. Em diferentes espécies agrícolas, a adaptabilidade e a estabilidade para PG estão fortemente ligadas ao ajuste da densidade de plantas para cada genótipo avaliado (Rambo et al., 2003; Shahin \& Valiollah, 2009; Silveira et al., 2010).

No espaçamento de $0,40 \mathrm{~m}$, na interação genótipo x ano, Hyola 432 apresentou MMG significativamente superior (4 g) a de Hyola 61 (3,5 g), em 2008, bem como maior enchimento de grãos. Já em 2009, não houve diferença entre os genótipos $(3,1 \mathrm{~g}$ para Hyola 432 e 3,4 g para Hyola 61). Hyola 61 mostrou similaridade entre os dois anos avaliados.

Em relação ao NSP, no espaçamento de $0,40 \mathrm{~m}$, no efeito principal densidade de plantas, houve tendência linear para redução nessa característica (Tabela 2). Tendência similar foi observada na análise dessa variável na interação genótipo $\mathrm{x}$ densidade, no espaçamento de $0,60 \mathrm{~m}$. No efeito principal ano, o NSP foi significativamente superior (273 síliquas por planta) em 2009, em comparação a 2008 (200 síliquas por planta). Quanto ao NGS, no efeito principal ano, a resposta foi contrária, tendo-se observado valores de 17 e 14 grãos por síliqua em 2008 e 2009, respectivamente. No efeito principal genótipo, Hyola 432 apresentou NSP significativamente superior (257 síliquas por planta), em comparação a Hyola 61 (206 síliquas por planta). Em culturas como soja e milho, o espaçamento de cultivo de $0,40 \mathrm{~m}$ entre linhas tem sido largamente utilizado. Portanto, agricultores da região noroeste do RS optam por utilizar esse espaçamento no momento da semeadura da canola, o que evita alterações na semeadora adaptada para as culturas de verão.
No espaçamento de $0,60 \mathrm{~m}$, em 2008 , os valores de MMG para Hyola 432 foram significativamente superiores aos observados em 2009 (4,0 e 3,6 g, respectivamente). Entretanto, a resposta de Hyola 61 foi contrária (3,4 g em 2008 e 3,8 g em 2009), por se tratar de um genótipo de ciclo longo e com maior potencial de crescimento de ramos, que, em menores densidades de cultivo, poderia reduzir a MMG, em virtude da maior partição de fotoassimilados direcionados aos ramos, fato também observado por Rambo et al. (2003), em soja. Hyola 432 se destacou como genótipo de maior enchimento médio de grãos (4 g), em 2008.

Nesse mesmo espaçamento, na avaliação do efeito principal ano para PG e NSP, o ano agrícola de 2009 foi significativamente superior (917 $\mathrm{kg} \mathrm{ha}^{-1}$ e 359 síliquas por planta, respectivamente) ao de 2008 (781 kg ha ${ }^{-1}$ e 303 síliquas por planta, respectivamente). Ao se considerar a média geral, a PG de Hyola 432 foi significativamente superior a de Hyola 61, com produção de 931 e $765 \mathrm{~kg} \mathrm{ha}^{-1}$, respectivamente.

O uso de espaçamentos maiores, como o de $0,60 \mathrm{~m}$ na canola, pode ser justificado quando alterações do microclima indicarem a necessidade de controle fitossanitário, pois a eficácia das medidas de controle de patógenos está relacionada à escolha de fungicidas, momento ideal para a aplicação e para a própria cobertura e penetração do princípio ativo sobre o dossel (Madalosso et al., 2010).

$\mathrm{Na}$ canola, as fontes de variação não contribuíram para a maior produtividade de grãos, no maior espaçamento entre linhas $(0,60 \mathrm{~m})$. Tourino et al. (2002) e Shahin \& Valiollah (2009), ao avaliar soja e canola, respectivamente, também observaram que a maior quantidade de luz incidente no interior do dossel não promoveu maior produtividade de grãos e maximizou o surgimento de espécies invasoras.

\section{Conclusões}

1. Ogenótipo Hyola 432 apresenta maior produção de grãos em comparação ao Hyola 61, independentemente do ano e da densidade de cultivo.

2. Os efeitos proporcionados pelo ano de cultivo influenciam mais a produção e os componentes da produtividade de grãos do que o potencial genético da cultivar e a densidade de cultivo.

3. O ajuste da densidade de plantas em canola é alterado pelo genótipo e pelo ano de cultivo. 


\section{Referências}

ANGADI, S.V.; CUTFORTH, H.W.; MCCONKEY, B.G.; GAN, Y. Yield adjustment by canola grown at different plant populations under semiarid conditions. Crop Science, v.43, p.1358-1366, 2003.

CARVALHO, F.I.F. de; LORENCETTI, C.; MARCHIORO, V.S.; SILVA, S.A. Condução de populações no melhoramento genético de plantas. Pelotas: Universidade Federal de Pelotas, 2008. 288p.

COIMBRA, J.L.M.; GUIDOLIN, A.F.; ALMEIDA, M.L. de; SANGOI, L.; ENDER, M.; MEROTTO JÚNIOR, A. Análise de trilha dos componentes do rendimento de grãos em genótipos de canola. Ciência Rural, v.34, p.1421-1428, 2004.

CRUZ, C.D. Programa Genes: versão Windows: aplicativo computacional em genética e estatística. Viçosa: UFV, 2001. 648p.

DALMAGO, G.A.; CUNHA, G.R. da; SANTI, A.; PIRES, J.L.F.; MÜLLER, A.L.; BOLIS, L.M. Aclimatação ao frio e dano por geada em canola. Pesquisa Agropecuária Brasileira, v.45, p.933-943, 2010.

DIEPENBROK, W. Yield analysis of winter oilseed rape (Brassica napus L.): a review. Field Crops Research, v.67, p.35-49, 2000.

JOHNSON, B.L.; HANSON, B.K. Row-spacing interactions on spring canola performance in the northern great plains. Agronomy Journal, v.95, p.703-708, 2003.

LEACH, J.E.; STEVENSON, H.J.; RAINBOW, A.J.; MULLEN, L.A. Effects of high plant populations on the growth and yield of winter oilseed rape (Brassica napus). Journal of Agricultural Science, v.132, p.173-180, 1999.

LIMA, W.F.; PÍPOLO, A.E.; MOREIRA, J.U.V.; CARVALHO, C.G.P. de; PRETE, C.E.C.; ARAIS, C.A.A.; OLIVEIRA, M.F. de; SOUSA, G.E. de; TOLEDO, J.F.F. Interação genótipo-ambiente de soja convencional e transgênica resistente a glifosato, no Estado do Paraná. Pesquisa Agropecuária Brasileira, v.43, p.729-736, 2008.

MADAlOSSO, M.G.; DOMINGUES, L. da S.: DEBORTOLI, M.P.; LENZ, G.; BALARDIN, R.S. Cultivares, espaçamento entrelinhas e programas de aplicação de fungicidas no controle de Phakopsora pachyrhizi Sidow em soja. Ciência Rural, v.40, p.2256-2261, 2010.

MEIER, U. Growth stages of mono- and dicotyledonous plants. 2.ed. Berlin: Federal Biological Research Centre for Agriculture and Forestry, 2001. 158p. (BBCH Monograph).
RAMBO, L.; COSTA, J.A.; PIRES, J.L.F.; PARCIANELLO, G.; FERREIRA, F.G. Rendimento de grãos da soja em função do arranjo de plantas. Ciência Rural, v.33, p.405-411, 2003.

SANTOS, H.G. dos; JACOMINE, P.K.T.; ANJOS, L.H.C. dos; OLIVEIRA, V.A. de; OLIVEIRA, J.B. de; COELHO, M.R.; LUMBRERAS, J.F.; CUNHA, T.J.F. (Ed.). Sistema brasileiro de classificação de solos. 2.ed. Rio de Janeiro: Embrapa Solos, 2006. $306 \mathrm{p}$.

SANTOS, H.P. dos; TOMM, G.O.; BAIER, A.C. Avaliação de germoplasmas de colza (Brassica napus L. var. oleifera) padrão canola introduzidos no sul do Brasil, de 1993 a 1996, na Embrapa Trigo. Passo Fundo: Embrapa Trigo, 2000. 10p. (Embrapa Trigo. Boletim de pesquisa online, 10).

SHAHIN, Y.; VALIOLLAH, R. Effects of row spacing and seeding rates on some agronomical traits of spring canola (Brassica napus L.) cultivars. Journal of Central European Agriculture, v.10, p.115-122, 2009.

SIDLAUSKAS, G.; BERNOTAS, S. Some factors affecting seed yield of spring oilseed rape (Brassica napus L.). Agronomy Research, v.1, p.229-243, 2003.

SILVEIRA, G. da; CARVALHO, F.I.F. de; OLIVEIRA, A.C. de; VALÉRIO, I.P.; BENIN, G.; RIBEIRO, G.; CRESTANI, M.; LUCHE, H.S.; SILVA, J.A.G. Efeito da densidade de semeadura e potencial de afilhamento sobre a adaptabilidade e estabilidade em trigo. Bragantia, v.69, p.63-70, 2010.

STRIEDER, M.L.; SILVA, P.R.F. da; RAMBO, L.; SANGOI, L.; SILVA, A.A. da; ENDRIGO, P.C.; JANDREY, D.B. Crop management systems and maize grain yield under narrow row spacing. Scientia Agricola, v.65, p.346-353, 2008.

SULTAN, S.E. Phenotypic plasticity for plant development, function and life history. Trends in Plant Science, v.5, p.537-542, 2000.

THOMAS, P. Canola grower's manual. Winnipeg: Canola Council of Canada, 2003. Available at: <http://www. canolacouncil.org/canola_growers_manual.aspx $>$. Accessed on: 14 Apr. 2011.

TOMM, G.O. Indicativos tecnológicos para produção de canola no Rio Grande do Sul. Passo Fundo: Embrapa Trigo, 2007. 68p. (Embrapa Trigo. Sistemas de produção, 4).

TOURINO, M.C.C.; REZENDE, P.M. de; SALVADOR, N. Espaçamento, densidade e uniformidade de semeadura na produtividade e características agronômicas da soja. Pesquisa Agropecuária Brasileira, v.37, p.1071-1077, 2002.

$\overline{\text { Recebido em } 28 \text { de março de } 2011 \text { e aprovado em } 17 \text { de outubro de } 2011}$ 